\title{
Dificuldades da assistência de enfermagem diante do quinto sinal vital: a dor
}

\author{
Fernanda Furtado da Paz*, Luciana de Paiva Rego**, Andrezza Ozela de Vilhena, M.Sc.***
}

*Acadêmica de Enfermagem da Universidade do Estado do Pará, ** Enfermeira, Pós-Graduanda em Enfermagem do Trabalho pela Faculdade Metropolitana da Amazônia, ***Docente da Universidade do Estado do Pará

\begin{abstract}
Resumo
Pela incidência e potencial de causar sofrimento e incapacidade, a dor, enquanto sintoma clínico, fez com que se transformasse num verdadeiro problema de saúde pública. O presente estudo é uma revisão integrativa que teve como objetivo retratar analiticamente os principais pontos que o profissional de enfermagem apresenta dificuldades, comprometendo a assistência prestada ao paciente com dor. Para a seleção dos artigos utilizou-se as bases de dados, Lilacs, Scielo, BDENF e Medline, obtendo uma amostra de 13 artigos. Após análise dos artigos incluídos na revisão, os resultados apontaram 3 eixos temáticos, que retratam sobre o registro e avaliação da dor, conhecimento científico do enfermeiro a respeito da dor e sobre as ações adotadas pelos enfermeiros para alívio da dor. Concluiu-se que o processo de educação em enfermagem náo está preparando enfermeiros para o correto manejo da dor, portanto, faz-se necessária uma atenção neste sentido, para que os futuros e atuais enfermeiros tenham o real entendimento da dor, possibilitando a prestaçáo de uma boa assistência de enfermagem.
\end{abstract}

Palavras-chaves: dor, assistência de enfermagem, educação em enfermagem.

\section{Abstract \\ Nursing care problems in managing the 5th vital sign, the pain}

Pain is the leading case of suffering and disability as a clinical symptom and, consequently, has become a public health problem. The present study is an integrative review that aimed to describe analytically the main points nursing professional have experienced difficulties, compromising quality of care to patients in pain. A literature review was conducted in Lilacs, Scielo, Medline and BDENF databases, and a sample of 13 studies was selected. After analyzing these articles, the results showed three thematic axes, which describe about the registration and pain assessment, scientific knowledge of nurses related to pain and nurses intervention to relieve pain. We concluded that educational process in nursing is not preparing nurses to provide proper pain management. We need, then, special attention to this theme so that current and future nurses really understand pain, providing high-quality care.

Key-words: pain, nursing care, nursing education. 


\section{Resumen}

\section{Dificultades de atención de enfermería ante el 5 signo vital, el dolor}

La incidencia y el potencial de causar sufrimiento y discapacidad, el dolor, como síntoma clínico, se ha convertido en un verdadero problema de salud pública. La presente revisión integradora tuvo como objetivo describir analíticamente las principales dificultades que el profesional de enfermería presenta, poniendo en peligro la atención prestada a los pacientes con dolor. Para la búsqueda de literatura científica, se utilizaron las bases de datos Lilacs, Scielo, Medline y BDENF, y la muestra incluyó 13 estudios. Después de analizar los estudios, los resultados apuntaron tres ejes temáticos, que describen sobre el registro y la evaluación del dolor, sobre el conocimiento científico de los enfermeros acerca del dolor y sobre las medidas tomadas por los enfermeros para el alivio del dolor. Se concluyó que el proceso de educación en enfermería no está preparando los enfermeros para el manejo adecuado del dolor. Es necesario, por lo tanto, atención en este sentido, para que los enfermeros actuales y futuros tengan el verdadero entendimiento del dolor, lo que permite calidad en la prestación de atención de enfermería.

Palabras-clave: dolor, cuidados de enfermería, educación en enfermería.

\section{Introdução}

Assim como os demais sinais vitais (temperatura, pulso, respiração e pressão arterial), a dor deve ser monitorada com o mesmo rigor, podendo ser avaliada ao mesmo tempo e no mesmo ambiente. Avaliar a dor e intervir em seu alívio vem sendo um processo altamente desafiante para os profissionais de saúde, portanto considerá-la como $5^{\circ}$ sinal vital é uma maneira de melhorar a qualidade do atendimento ao paciente [1].

Há duas classificações para a dor: aguda e crônica. A dor aguda está relacionada a traumatismos, infecçôes ou inflamaçôes, havendo expectativa de desaparecimento após a cura da lesáo. Tem como característica o aparecimento de respostas neurovegetativas associadas (elevação da pressão arterial, taquicardia, taquipneia, entre outras). Já a dor crônica persiste após o tempo razoável para a cura de uma lesão ou está associada a processos patológicos crônicos, causando dor contínua ou recorrente. Ansiedade e depressão são respostas frequentemente associadas ao quadro clínico e geralmente não há respostas neurovegetativas associadas ao sintoma [2].

Em virtude do caráter subjetivo e complexo da dor, é imprescindível compreendê-la e, consequentemente, acreditar nos relatos do paciente, pois a comunicação seja de forma verbal ou comportamental é a única forma que o profissional tem de mensurar a dor [3].

Os enfermeiros, assim como a equipe de enfermagem, estão sempre presentes e mantêm uma relação de maior proximidade com o paciente, passando maior tempo com eles do que qualquer outro membro da equipe multiprofissional, portanto deveriam estar capacitados para avaliar a dor nos pacientes, possuindo plena condição para assegurar o controle da dor por meio de sua avaliação, de sua evolução efetiva e de seu tratamento [3].

Partindo deste ponto, o estudo em questão tem como objetivo identificar, através de uma revisão integrativa da literatura, os principais pontos que os profissionais de enfermagem apresentam dificuldades ou desconhecimento, comprometendo a prestação de uma assistência adequada ao paciente com dor.

A compreensão da dor, enquanto fenômeno complexo que importa entender nas suas várias dimensôes, implica e questiona especialidades diversas e, por isso, faz-se necessário uma assistência multidisciplinar [4], ou seja, a equipe de enfermagem interagindo com os demais profissionais da área de saúde, a fim de proporcionar a melhor assistência possível ao paciente.

A dor resulta em alteraçóes biológicas, psicossociais e sofrimento. Há prejuízo de sono, do trabalho, da movimentação e deambulação, ocorre alteração do humor, da capacidade de concentração, do relacionamento familiar, da atividade sexual e apreciaçáo pessimista e desesperançada da vida. É um fenômeno cuja etiologia e manifestação são multidimensionais, com base teórica advinda de várias ciências. Os aspectos biológicos, emocionais e culturais da experiência dolorosa justificam o uso de intervençóes múltiplas, farmacológicas e não farmacológicas, para o seu alívio [5].

Mesmo a dor sendo uma das experiências mais comuns na população, não recebe uma avaliação eficaz. Em virtude disso, dá-se a importância do comprometimento dos profissionais de enferma- 
gem, assim como dos demais membros da equipe multidisciplinar, para que juntos possam trabalhar alcançando sucesso no controle e manejo da dor.

\section{Métodologia}

Trata-se de uma revisão integrativa da literatura em que foram utilizadas as bases de dados Lilacs, Scielo, BDENF e Medline, durante limites temporais de 2007 a 2010. Esse período foi escolhido, pois a intenção deste estudo era o de coletar informaçóes recentes, para que os próximos estudos venham tentando solucionar este problema, fazendo com que os futuros profissionais de enfermagem não apresentem a mesma carência na prestação desta assistência. Para a seleçáo dos textos, fez-se uma busca sobre as produçóes do conhecimento referente à dor, tendo como descritores: dor, assistência de enfermagem e educação em enfermagem. A partir da leitura dos resumos, os artigos foram selecionados tendo em vista critérios de inclusão e exclusão. Foram incluídos neste trabalho: pesquisas e livros que abordassem o tema em estudo. A busca realizada foi limitada a artigos publicados em português, para que se pudesse identificar a realidade dos profissionais de enfermagem em nosso país. Assim foram encontrados 21 artigos referentes aos descritores, sendo excluídos aqueles que não atendiam aos critérios estabelecidos, que são: ser publicado em português; entre os anos de 2007 - 2010 e abordar um dos assuntos referentes aos descritores. Ao final, foram selecionados 13 artigos, sendo organizados em fichas nas quais constavam dados de identificação, ano de publicação dos artigos e uma síntese evidenciando os principais pontos de cada texto. Por se tratar de uma revisão de literatura, o presente estudo não foi apresentado a um Comitê de Ética em Pesquisa com Seres Humanos. No entanto, são respeitados todos os aspectos éticos no que se refere à citação de todas as informaçôes e ideias consultadas.

\section{Resultados e discussão}

Dos 13 artigos selecionados, 2 foram publicados em 2010, 4 em 2009, 3 em 2008 e 4 em 2007, apontando que houve uma estagnação em estudos envolvendo esta temática. Em relação ao tipo de periódico onde foram publicados os artigos, houve predominância daqueles onde os temas abordados eram relativos aos atuais campos da saúde numa perspectiva da área de enfermagem. A partir da análise do conteúdo das evidências foi possível identificar três (3) eixos temáticos importantes para a assistência de enfermagem diante da dor:

- Eixo 1 - Registro e avaliaçáo da dor: um ponto comum a todos os artigos é que a dor, em especial a crônica, não é corretamente tratada e documentada pelos enfermeiros, devido à inadequada avaliação inicial ocasionada pela falta de rigor e seriedade em sua mensuração. Isso ocorre devido a vários fatores, como: carga suplementar de trabalho; dificuldade em ouvir o que o doente tem a dizer; necessidade de ser persistente, rigoroso e metódico durante a avaliação; necessidade de mensurá-la diariamente; dificuldade de manter uma relaçáo de confiança para dar ao doente oportunidade para se exprimir sobre a dor que sente; dificuldade em empenhar-se na procura de respostas eficazes de prevenção e de controle da dor [6]. Outra dificuldade encontrada pelos enfermeiros está relacionada àqueles pacientes que apresentam dificuldades cognitivas ou verbais, que não podem relatar verbalmente a dor, fazendo com que o enfermeiro passe a observar a sinalização não-verbal como forma de linguagem alternativa, o que compromete ainda mais essa avaliação, pois fica ainda mais difícil compreender o que o paciente quer dizer através de gestos ou comportamentos. Não é só a falta de cuidados para com a dor que é inadequada, a documentação também é comprometida, sendo consequência de uma ineficaz avaliação à dor. Esta falha deve ser urgentemente modificada, pois tais informações são compartilhadas entre os diversos plantóes e equipe de enfermagem, garantindo a continuidade da assistência e tratamento pelos profissionais de outros turnos. Os enfermeiros reconhecem a importância de se avaliar corretamente o $5^{\circ}$ sinal vital e, por isso, batalham por uma mudança em toda equipe multidisciplinar, bem como na própria organização de saúde, através da implementação da educação e treinamento contínuo para modificar comportamentos e práticas rotineiras desses profissionais, aperfeiçoando a assistência como um todo. Os pacientes que têm a intensidade da dor avaliada e registrada sistematicamente apresentam considerável redução do quadro doloroso, quando comparado aos que não são devidamente assistidos. A equipe de enfermagem, devido à maior proximidade com o paciente, é quem deveria melhor identificar, 
avaliar e notificar a dor, programar a terapêutica farmacológica prescrita, prescrever algumas medidas não farmacológicas e avaliar a analgesia [3] . Ou seja, na prática, é quem deveria organizar o gerenciamento da dor, no entanto, publicaçóes e informaçóes sobre o papel de enfermeiras na administração da dor são praticamente inexistentes [7], podendo-se tentar justificar o déficit de conhecimento e falta de êxito em sua avaliação, uma vez que não se tem dado a devida importância que este assunto merece.

- Eixo 2 - Conhecimento científico do enfermeiro a respeito da dor: Os enfermeiros tendem a ter mais conhecimentos acerca do tratamento da dor e menos conhecimentos acerca das intervençóes na dor [8]. Estudos constataram que esta é uma falha que vem desde a graduação, levando-os a não avaliarem a dor de forma sistemática, a subestimarem a frequência de ocorrência da dor e ignorarem o impacto devastador da dor para o indivíduo [9]. O domínio técnico-científico contribui para uma melhor assistência ao paciente com dor, no entanto, referente a esta temática, constatou-se que há relatos de déficit de conhecimento, inadequada avaliaçáo e insuficiente registro sobre dor e analgesia [9]. Apesar de o grande progresso observado no conhecimento científico e tecnológico, a causa da existência da dor e seu controle ainda não são bem compreendidos pelos profissionais de saúde. Devido a esse conhecimento científico deficitário, existem algumas lacunas que interferem na abordagem da dor, como a não valorização da queixa dolorosa e a influência dos valores, preconceitos e experiências pessoais que estão presentes na avaliação da dor. Apesar da visibilidade dos profissionais com relação aos seus efeitos prejudiciais e dos fatores que influenciam na sua existência, o pouco conhecimento por parte dos enfermeiros sobre a dor e seu tratamento constitui-se numa das principais barreiras para promoçáo de conforto nessa situação [10]. Diante de todos os fatores citados acima, de forma especial à complexidade de todas as características do fenômeno "dor" e também da sua importância no contexto clínico, é que se torna fundamental a educação continuada, direcionada à equipe de enfermagem, para propiciar conhecimentos técnico-científicos que beneficiarão o manuseio das diversas dimensóes da dor, visto que os enfermeiros são gerenciado- res do cuidado e corresponsáveis pela qualidade da assistência [10]. As instituiçóes de ensino, bem como os docentes de enfermagem, devem assegurar que todos os estudantes tenham conhecimento sobre dor e sofrimento, e que eles entendam a necessidade de sua avaliação e do registro sistemático. De forma especial, os cursos de graduação possuem a responsabilidade de garantir aos acadêmicos de enfermagem, e futuros enfermeiros, os conhecimentos e habilidades necessários para saber abordar a dor e compartilhar com toda a equipe [11].

- Eixo 3 - Açóes adotadas pelos enfermeiros para o alivio da dor: O alívio da dor é um pré-requisito para que o paciente obtenha uma ótima recuperação e qualidade de vida. Algumas das consequências para o paciente, sem o alívio da dor, incluem sofrimento, ansiedade, medo, depressão, raiva, imobilidade e isolamento e, tais consequências, podem contribuir para um decréscimo da qualidade de vida [10]. Os enfermeiros procuram aliviar a dor por meio de diferentes açôes e estratégias de interação com o paciente e intervençóes sobre o ambiente hospitalar, a fim de promover o conforto, manter uma interação com o paciente, minimizar o barulho, valorizar e partilhar a dor, ouvir o paciente, explicar o motivo da dor, medicar, desviar a atençáo do paciente da dor, oferecer apoio psicológico e orientar quanto às medidas tomadas para alívio da dor [12]. Outro ponto importante é a prescrição de analgésicos pelo médico, para que o enfermeiro possa administrá-lo garantindo o alívio da dor. A analgesia controlada é um tratamento recente no manejo da dor, ajudando na promoçáo do conforto do paciente. É competência do enfermeiro e de outros profissionais o alívio da dor. O uso de analgésicos é uma das formas mais utilizadas para analgesia da dor e deve ser indicada avaliando a intensidade, as qualidades e o tipo de dor sentida [1]. A farmacologia é uma forma para controlar e combater a dor, podendo estar associada a outras medidas que independem da prescrição médica. Os enfermeiros podem realizar técnicas de relaxamento e distração proporcionando ao paciente uma maior sensação de controle da dor. A distração consiste em direcionar a atenção a outros focos, como a televisão, música, figuras, livros e artes manuais. Essa técnica pode ser realizada quando 
se deseja executar um procedimento doloroso, ou durante o período em que se espera pelo efeito analgésico de medicamentos administrados [13]. A dificuldade em se modificar intervençôes inadequadas e a falta de açóes para a prevenção da dor é o motivo do insucesso em proporcionar alívio adequado ao paciente.

\section{Conclusão}

A equipe de enfermagem, por manter contato direto com o paciente, é quem deveria estar mais bem preparada para prestar assistência ao paciente com dor, desempenhando papel fundamental como integrante da equipe multidisciplinar.

Percebe-se que a graduação em enfermagem não está preparando adequadamente os futuros enfermeiros para o manejo, avaliação e alívio da dor. Os enfermeiros, tanto os atuantes como os futuros profissionais, precisam ter o real entendimento da dor e suas consequências ao paciente, para que possam prestar uma assistência respeitando o relato do paciente e oferecendo o devido tratamento para controle e alívio da dor.

Em decorrência desses problemas na assistência de enfermagem à dor, faz-se necessária à conscientização de toda a equipe multiprofissional e principalmente dos enfermeiros, para que juntos alcancem o bem estar do paciente. Sendo assim, é indispensável que a enfermagem tenha a iniciativa de buscar novos conhecimentos e treinamentos para lidar com o $5^{\circ}$ sinal vital, a dor.

\section{Referências}

1. Posso IP, Pires PWA. A dor como $5^{\circ}$ sinal vital: controle da dor aguda no pós-operatório. Sáo Paulo: Instituto Central do Hospital das Clínicas da Faculdade de Medicina da Universidade de São Paulo; 2006.

2. Fernandes RA, Salum MJ, Teixeira MB, Lemni RCA, Miura M. Anotaçôes de enfermagem. Rev Esc Enferm USP 1981;15(1):63-7.

3. Cailliet R. Dor em crianças. In: Cailliet R. Dor: mecanismos e tratamento. Porto Alegre: Artmed; 1999. p.289-92.

4. Riley JB. Comunicaçáo em Enfermagem. $4^{\mathrm{a}}$ ed. Loures: Lusociência; 2004.

5. Yates P, Dewar A, Edwards H, Fentiman B, Najman J, Nash R, et al. The prevalence and perception of pain amongst hospital in-patients. J Clin Nurs 1998;7(6):521-30.

6. Davis MP, Walsh D. Cancer pain: how to measure the fifth vital sign. Cleve Clin J Med 2004;71(8):625-32.

7. Ministério da Saúde, Instituto Nacional do Câncer. Cuidados paliativos oncológicos: controle da dor. Rio de Janeiro: INCA; 2001.

8. Silva LMH, Zago MMF. O cuidado do doente oncológico com dor crônica na óptica do enfermeiro. Rev Latinoam Enferm 2001;4:44-9.

9. Silva YB, Pimenta CAM. Análise dos registros de enfermagem sobre dor e analgesia em doentes hospitalizados. Rev Esc Enferm USP 2003;37(2):109-18.

10. Basso L, Sinsen CD, Giasson G. Avaliação da dor: conhecimento científico versus a prática de enfermagem. Livro-Temas do $56^{\circ}$ Congresso Brasileiro de Enfermagem; Enfermagem hoje: coragem de experimentar muitos modos de ser [livro em formato eletrônico]; 2004 Out 24-29. [citado 2011 Set 16]. Disponível em URL: http://bstorm.com.br/enfermagem.

11. Vila VSC, Mussi FC. O alívio da dor de pacientes no pós-operatório na perspectiva de enfermeiros de um centro de terapia intensiva. Rev Esc Enferm USP 2001;35(3):300-7.

12. Pereira LV. Estimaçáo de categorias e descritores de dor pós-operatória: um enfoque experimental [Dissertação]. Ribeirão Preto: Escola de Enfermagem de Ribeirão Preto da Universidade de Sáo Paulo; 1996.

13. Sofaer B. Dor manual prático. $2^{\mathrm{a}} \mathrm{ed}$. Rio de Janeiro: Revinter; 1994. 